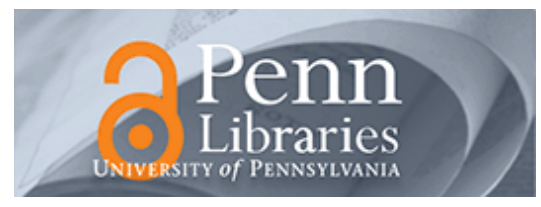

University of Pennsylvania

ScholarlyCommons

Operations, Information and Decisions Papers

Wharton Faculty Research

4-1996

\title{
Paradox Lost? Firm-Level Evidence on the Returns to Information Systems Spending
}

\author{
Erik Brynjolfsson
}

Lorin. M. Hitt

University of Pennsylvania

Follow this and additional works at: https://repository.upenn.edu/oid_papers

Part of the Other Computer Sciences Commons

\section{Recommended Citation}

Brynjolfsson, E., \& Hitt, L. M. (1996). Paradox Lost? Firm-Level Evidence on the Returns to Information Systems Spending. Management Science, 42 (4), 541-558. http://dx.doi.org/10.1287/mnsc.42.4.541

This paper is posted at ScholarlyCommons. https://repository.upenn.edu/oid_papers/200

For more information, please contact repository@pobox.upenn.edu. 


\title{
Paradox Lost? Firm-Level Evidence on the Returns to Information Systems Spending
}

\begin{abstract}
The "productivity paradox" of information systems (IS) is that, despite enormous improvements in the underlying technology, the benefits of IS spending have not been found in aggregate output statistics. One explanation is that IS spending may lead to increases in product quality or variety which tend to be overlooked in the aggregate statistics, even if they increase output at the firm-level. Furthermore, the restructuring and cost-cutting that are often necessary to realize the potential benefits of IS have only recently been undertaken in many firms.

Our study uses new firm-level data on several components of IS spending for 1987-1991. The dataset includes 367 large firms which generated approximately 1.8 trillion dollars in output in 1991 . We supplemented the IS data with data on other inputs, output, and price deflators from other sources. As a result, we could assess several econometric models of the contribution of IS to firm-level productivity.

Our results indicate that IS spending has made a substantial and statistically significant contribution to firm output. We find that the gross marginal product (MP) for computer capital averaged $81 \%$ for the firms in our sample. We find that the MP for computer capital is at least as large as the marginal product of other types of capital investment and that, dollar for dollar, IS labor spending generates at least as much output as spending on non-IS labor and expenses. Because the models we applied were similar to those that have been previously used to assess the contribution of IS and other factors of production, we attribute the different results to the fact that our data set is more current and larger than others explored. We conclude that the productivity paradox disappeared by 1991, at least in our sample of firms.
\end{abstract}

\section{Keywords}

information technology, productivity, production function, computers, software, IS budgets

\section{Disciplines}

Other Computer Sciences 


\title{
Paradox Lost?
}

\section{Firm-level Evidence of High Returns to Information Systems Spending}

\author{
by
}

\author{
Erik Brynjolfsson
}

\author{
Lorin Hitt
}

MIT Sloan School

Copyright (C 1993, 1994 Erik Brynjolfsson and Lorin Hitt

All Rights Reserved

March 15, 1993

Revised October, 1993 and February, 1994

Authors' Address:

MIT room E53-313

Cambridge, MA 02139

tel: 617-253-4319

email: brynjolfsson@mit.edu

orlhitt@sloan.mit.edu

This research has been generously supported by the MIT Center for Coordination Science, the MIT Industrial Performance Center, and the MIT International Financial Services Research Center. We thank Martin Neil Baily, Rajiv Banker, Ernst Berndt, Geoff Brooke, Zvi Griliches, Bronwyn Hall, Susan Humphrey, Dan Sichel, Robert Solow, Paul Strassmann, Diane Wilson, three anonymous referees and seminar participants at Boston University, Citibank, Harvard Business School, the International Conference on Information Systems, MIT, National Technical University in Singapore, Stanford University, the University of California at Irvine and the U.S. Federal Reserve for valuable comments, while retaining responsibility for any errors that remain. We are also grateful to International Data Group for providing essential data. An abbreviated version of this paper was published in the Proceedings of the International Conference on Information Systems, 1993, under the title "Is Information Systems Spending 


\section{Table of Contents:}

\section{INTRODUCTION}

1.1 Previous research on IT and productivity

1.2 Data Issues

1.3 Theoretical Issues

2. METHODS AND DATA

2.1 Estimating Procedures

2.3 Data Sources and Variable Construction

2.4 Potential Data Problems

\section{RESULTS}

\section{$\underline{3.1}$ Basic results}

3.2 What factors affect the rates of return for computers?

3.3 Sensitivity Analysis and Possible Biases - Econometric Issues

\section{DISCUSSION}

$\underline{4.1 \text { Comparison with earlier research }}$

4.2 Managerial Implications

\section{CONCLUSION}

6. TABLES AND FIGURES

7. BIBLIOGRAPHY

\section{Footnotes}

\section{ABSTRACT}

The "productivity paradox" of information systems (IS) is that, despite enormous improvements in the underlying technology, the benefits of IS spending have not been found in aggregate output statistics. One explanation is that IS spending may lead to increases in product quality or variety which tend to be overlooked in aggregate output statistics, even if they increase sales at the firm-level. Furthermore, the restructuring and cost-cutting that are often necessary to realize the potential benefits of IS have only recently been undertaken in many firms.

Our study uses new firm-level data on several components of IS spending for 1987-1991. The dataset includes 367 large firms which generated approximately \$1.8 trillion dollars in output in 1991. We supplemented the IS data with data on other inputs, output, and price deflators from other sources. As a result, we could assess several econometric models of the contribution of IS to firm-level productivity.

Our results indicate that IS have made a substantial and statistically significant contribution to firm output. We find that between 1987 and 1991, gross return on investment (ROI) for computer capital averaged $81 \%$ for the firms in our sample. We find that the ROI for computer capital is greater than the return to other types of capital investment and that IS labor spending generates several times as much output as spending on non-IS labor and expenses. Because the models we applied were essentially the same as those that have been previously used to assess the contribution of IS and other factors of production, we attribute the different results to the fact that our data set is more current and larger than others explored. We conclude that the "productivity paradox" disappeared by 1991, at least in our sample of firms.

\section{INTRODUCTION}


Spending on information systems (IS), and in particular information technology (IT) capital, is widely regarded as having enormous potential for reducing costs and enhancing the competitiveness of American firms. Although spending has surged in the past decade, there is surprisingly little formal evidence linking it to higher productivity. Several studies, such as those by Loveman (1994) and by Barua, Kriebel \& Mukhopadhyay (1991) have been unable to reject the hypothesis that computers add nothing at all to total output, while others estimate that the marginal benefits are less than the marginal costs (Morrison \& Berndt, 1990).

This "productivity paradox" has alarmed managers and puzzled researchers. American corporations have spent billions of dollars on computers and many firms have radically restructured their business processes to take advantage of computers. If these investments have not increased the value produced or reduced costs, then management must rethink their IS strategies. Roach (1987), who was among the first to identify the productivity shortfall in the 1980s, is currently more optimistic about the current prospects for productivity growth because many firms have finally begun to realize the potential labor savings enabled by IT. However, because none of the previous estimates of IT productivity were based on recent data, this hypothesis remains untested.

This study considers new evidence and finds sharply different results from previous studies. Our dataset is based on five annual surveys of several hundred large firms for a total of 1121 observations [1] over the period 1987-1991. The firms in our sample generated approximately \$1.8 trillion dollars worth of gross output in the United States in 1991, and their value-added accounted for about 13\% of the 1991 US GDP of $\$ 4.86$ trillion [2] (Council of Economic Advisors, 1992). Because the identity of each of the participating firms is known, we were able to supplement the IS data with data from several other sources. As a result, we could assess several econometric models of the contribution of IS to firm-level productivity.

Our examination of these data indicates that IS have made a substantial and statistically significant contribution to the output of firms (Figure 1). Our point estimates indicate that, dollar for dollar, spending on computer capital created more value than spending on other types of capital. We find that the contribution of IS to output does not vary much across years, although there is weak evidence of a decrease over time. We also find some evidence of differences across various sectors of the economy. Technological factors also appear to affect returns. For instance, we find that neither firms which relied heavily on mainframes, nor firms which emphasized PC usage performed as well as firms that invested in a mix of mainframes and personal computers (PCs).

For the firms in our sample, we estimate that the gross return on investment for computers to be over $50 \%$ annually. Considering a 95\% confidence interval around our estimates, we can reject the hypothesis that computers add nothing to total output. Furthermore, several of our regressions suggest that the return on investment for computers is significantly higher than the return on investment for other types of capital. Our findings suggest that if there ever was a "productivity paradox", it disappeared in the 1987-1991 period, at least for our sample of large firms.

\subsection{Previous research on IT and productivity}

There is a broad literature on IT value which has been recently reviewed in detail elsewhere (Brynjolfsson, 1993; Wilson, 1993). Many of these studies examined correlations between IT spending ratios and various performance measures, such as profits or stock returns (Dos Santos, Peffers \& Mauer, 1993; Harris \& Katz, 1988; Strassmann, 1990), and some found that the correlation was either zero or very low. In interpreting these findings, it is important to bear in mind that economic theory predicts that in equilibrium, high computer investors would not, on average, have higher profitability or stock market returns. Managers should be as likely to over-spend as to under-spend, so high spending should not necessarily be "better". Where correlations are found, they should be interpreted as indicating an 
unexpectedly high or low contribution of information technology, as compared to the performance that was anticipated when the investments were made. Thus, perhaps counter-intuitively, zero or weak correlations between the percentage of spending allocated to IT and profitability would not indicate a low payoff to computers.

To examine the contribution of IT, it is helpful to work within a well-defined theoretical framework. For instance, Alpar \& Kim (1990) found that methods based firmly on production theory from economics could yield insights that were not apparent when more loosely constrained statistical analyses were performed. The economic theory of production provides a particularly relevant framework. This theory posits that the output of a firm is related to its inputs via a production function and that each input should make a positive contribution to output. A further prediction of the theory is that the marginal cost of the last unit of each input should just equal the marginal benefit produced by that input. Literally hundreds of studies have estimated production functions with various inputs, and the predictions of economic theory have generally been confirmed (See Berndt, 1991, especially chapters 3 and 9, for an excellent review of many of these studies).

The "productivity paradox" is most accurately linked to a subset of studies based on the theory of production which either found no positive correlation overall (Barua, Kriebel \& Mukhopadhyay, 1991; Loveman, 1994), or found that benefits fell short of costs (Morrison \& Berndt, 1990). Using a subset of the PIMS database [3], Loveman (1994) concluded: "Investments in IT showed no net contribution to total output," and Barua, Kriebel and Mukhudpadhyay (1991) found that computer investments are not significantly correlated with increases in return on assets. Similarly, Morrison and Berndt (1990) examined industry-level data using a production function that controlled for changes in other inputs and found that each dollar spent on "high tech" capital [4]increased measured output by only 80 cents on the margin.

Although previous work provides little econometric evidence that computers improve productivity, Brynjolfsson's (1993) review of the overall literature on this "productivity paradox" concludes that the "shortfall of evidence is not necessarily evidence of a shortfall." He notes that increases in product variety and quality should properly be counted as part of the value of output, but that the price deflators that the government currently uses to remove the effects of inflation do not properly reflect this value. As a result, inflation is overestimated and real output is underestimated by an equivalent amount (because real output is estimated by multiplying nominal output by a price deflator). In addition, as with any new technology, a period of learning, adjustment and restructuring may be necessary to reap its full benefits. Accordingly, he argues that "mismeasurement" and "lags" are two of four viable explanations (along with "redistribution" and "mismanagement") for the collected findings of earlier studies. This leaves the question of computer productivity open to continuing debate.

Industry-level output statistics have historically been the only data that are available for a broad crosssection of the economy. In a related study using much of the same data as the Morrison \& Berndt (1990) study, Berndt and Morrison (1994) conclude, "...there is a statistically significant negative relationship between productivity growth and the high-tech intensity of the capital." However, they also point out: "it is possible that the negative productivity results are due to measurement problems...". Part of the difficulty is that industry-level data does not provide sufficient detail to distinguish firms within a particular industry which invest heavily in IT from those with low IT investments. Only comparisons among industries can be made, yet these comparisons can be sensitive to price deflators used, which in turn depend on the assumptions about how much quality improvement has occurred in each industry. Firm-level production functions, on the other hand, will better reflect the "true" outputs of the firm, insofar as the increased sales at each firm can be directly linked to its use of computers and other inputs, and all the firms are subject to the same industry-level price deflator.

On the other hand, a weakness of firm-level data is that it can be painstaking to collect, and therefore, 
studies with firm level data have historically focused on relatively narrow samples. This has made it difficult to draw generalizable results from these studies. For instance, Weill (1992) found some positive impacts for investments in some categories of IS but not for overall IS spending. However, the 33 strategic business units in his sample from the valve manufacturing industry accounted for less than \$2 billion in total sales, and he notes, "The findings of the study have limited external validity." (Weill, 1992.) By the same token, the Loveman (1994) and Barua, Kriebel and Mukhudpadhyay (1991) studies were based on data from only 20 firms in the 1978-82 period and derived only fairly imprecise estimates of IT's relationship to firm performance.

\subsection{Data Issues}

The imprecision of previous estimates highlights an inherent difficulty of measuring the benefits of IT investment. To better understand the perceived benefits, we conducted several interviews with managers which revealed that they focus on five principal rationales for investing in IT: labor savings, improved quality, greater product variety, better customer service, and faster response time. In principle, all of these benefits should be incorporated in the government price deflators that convert nominal sales to real output. In practice, the value of many of the benefits of IT, other than labor savings, are not well captured in aggregate productivity or output statistics. [5]

Computers represent on the order of $1 \%$ of firms' expenses in most historical data sets. This makes it very difficult to distinguish the contribution of IT from random shocks that affect productivity. As Simon (1984) has observed:

In the physical sciences, when errors of measurement and other noise are found to be of the same order of magnitude as the phenomena under study, the response is not to try to squeeze more information out of the data by statistical means; it is instead to find techniques for observing the phenomena at a higher level of resolution. The corresponding strategy for economics is obvious: to secure new kinds of data at the micro level.

A convincing assessment of IS productivity would ideally employ a sample which included a large share of the economy (as in the Berndt and Morrison studies), but at a level of detail that disaggregated inputs and outputs for individual firms (as in Loveman (1994), Barua et al. (1991), and Weill (1992)). Furthermore, because the recent restructuring of many firms may have been essential to realizing the benefits of IS spending, the data should be as current as possible. Lack of such detailed data has hampered previous efforts. While our paper applies essentially the same models as those used in earlier studies, we use new, firm-level data which is more recent, more detailed and includes more companies. We believe this accounts for our sharply different results.

\subsection{Theoretical Issues}

As discussed above, Brynjolfsson (1993) presents a number of hypotheses for explaining the productivity paradox, including the possibility that it is an artifact of mismeasurement. We consider this possibility in this paper.

More formally, we statistically test the following hypotheses:

H1) The output contributions of computer capital and IS staff labor are positive;

H2) The output contributions of computer capital and IS staff labor are greater than their costs.

The "productivity paradox" of computers questions whether these hypotheses are empirically valid.

In our analysis, we build on a long research stream which applies production theory to determine the 
contributions of various inputs to output. [6] This approach uses economic theory to determine the set of relevant variables and to define the structural relationships among them. The relationship can then be estimated econometrically and compared with the predictions of economic theory. In particular, for any given set of inputs, the maximum amount of output that can be produced, according to the known laws of nature and existing "technology", is determined by a production function. As noted by Berndt (1991), various combinations of inputs can be used to produce a given level of output, so a production function can be thought of as pages of a book containing alternative blueprints. This is essentially an engineering definition, but business implications can be drawn by adding an assumption about how firms behave, such as profit maximization or cost minimization. Under either assumption, no inputs will be "wasted", so the only way to increase output for a given production function is to increase at least one input.

The theory of production not only posits a relationship among inputs and output, but also posits that this relationship may vary depending on particular circumstances. Many of these differences can be explicitly modeled by a sufficiently general production function without adding additional variables. For instance, it is common to assume that there are constant returns to scale, but more general models will allow for increasing or decreasing returns to scale. In this way, it is possible to see whether large firms are more or less efficient than smaller firms. Other differences may have to do with the economic environment surrounding the firm, and are not directly related to inputs. Such differences are properly modeled as additional "control" variables. Depending on prices and desired levels of output, different firms may choose different combinations of inputs and outputs, but they will all adhere to the set defined by their production function. The neoclassical economic theory of production has been fairly successful empirically, despite the fact that it treats firms as "black boxes" and thus ignores history or details of the internal organization of firms. Of course, in the real world, such factors can make a significant difference and recent advances in the theory of the firm may enable them to be more rigorously modeled as well.

To operationalize the theory for our sample, we assume that the firms in our sample produce a quantity of OUTPUT (Q) via a production function (F), whose inputs are COMPUTER CAPITAL (C), NON-COMPUTER CAPITAL (K), IS STAFF labor (S), and OTHER LABOR AND EXPENSES (L). [7] These inputs comprise the sum total of all spending by the firm and all capitalized investment.

Economists historically have not distinguished computer capital from capital, lumping them together as a single variable. Similarly, previous estimates of production functions have not distinguished IS staff labor from other types of labor and expenses. However, for our purposes, making this distinction will allow us to directly examine hypothesis such as $\mathrm{H} 1$ and $\mathrm{H} 2$ above. We seek to allow for fairly general types of influences by allowing for any type of environmental factors which affect the industry or business sector (i) in which the company operates and year (t) in which the observation was made. [8] Thus, we can write:

$\mathrm{Q}=\mathrm{F}(\mathrm{C}, \mathrm{K}, \mathrm{S}, \mathrm{L} ; \mathrm{i}, \mathrm{t})(1)$

Output and each of the input variables can be measured in either physical units or dollars. If measured in dollar terms, the results will more closely reflect the ultimate objective of the firm (profits, or revenues less costs). However, this approach requires that we account for inflation and the changing prices of different inputs and outputs over time and in different industries. This can be done by multiplying the nominal dollar value of each variable in each year by an associated deflator to get the real dollar values. This approach also partially accounts for changes in product quality or variety to the extent that changes in output characteristics are incorporated into the price deflators.

Some companies will be more efficient than others at converting inputs to outputs. The amount of output that can be produced for a given unit of a given input is often measured as the return on investment of the input. When examining differences in the returns of a factor across firms or time periods, it is important to control for the effects of changes in the other inputs to production. One way to do this is to assume that the production function, F, has some functional form, and then estimate its parameters. This approach has 
been widely applied empirically (Berndt, 1991, pp. 449-460).

The economic theory of production places certain technical constraints on the choice of functional form, such as quasi-concavity and monotonicity (Varian, 1992). In addition, we observe that firms use multiple inputs in production, so the functional form should also include the flexibility to allow continuous adjustment between inputs as the relative prices of inputs change. [9] Perhaps the simplest functional form that relates inputs to outputs and is consistent with these constraints is the Cobb-Douglas specification, variants of which have been used since 1896 (Berndt, 1991). This specification is probably the most common one used when estimating production functions and remains the standard for studies such as ours, which seek to account for output growth by looking at inputs and other factors. [10]

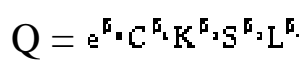

In this specification, b1 and b3 are the output elasticity of COMPUTER CAPITAL and information systems staff (IS STAFF), respectively. [11]If the coefficients b0 - b4 sum to 1, then the production function exhibits constant returns to scale. However, increasing or decreasing returns to scale can also be modeled with the above function. The principal restriction implied by the Cobb-Douglas form is that the elasticity of substitution between factors is constrained to be equal to -1 . This means that as the price of a particular input increases, the amount of the input employed will decrease by a proportionate amount, and the quantities other inputs will increase to maintain the same level of output. As a result, this formulation is not appropriate for determining whether inputs are substitutes or complements. Other more complicated functional forms such as the Transcendental Logarithmic, or Translog, formulation relaxes this restriction. We consider several other functional forms in section 3.3 and confirm the appropriateness of the Cobb-Douglas specification for estimating output elasticities.

The remainder of the paper is organized as follows: in section 2, we describe the statistical methodology and data of our study. The results are presented in section 3 . In section 4, we conclude with a discussion of the implications of our results.

\section{METHODS AND DATA}

\subsection{Estimating Procedures}

The basic Cobb-Douglas specification is obviously not linear in its parameters. However, by taking logarithms of equation (2) and adding an error term (e), one can derive an equivalent equation that can be estimated by linear regression. For estimation, we have organized the equations as a system of five equations, one for each year: [12]

$$
\begin{aligned}
& \log \mathrm{Qi}_{1,87}=\text { b0 + b1 Log Ci,87 + b2 Log Ki,87 + b3 Log Si,87 + b4 Log Li,87 + e87 (3a) } \\
& \log \mathrm{Qi}_{\mathrm{i}, 88}=\mathrm{b} 0+\text { b1 } \log \mathrm{Ci}, 88+\text { b2 } \log \mathrm{Ki}, 88+\text { b3 } \log \mathrm{Si}, 88+\text { b4 Log Li,88 + e88 (3b) } \\
& \log \mathrm{Qi}_{1,89}=\text { b0 + b1 Log Ci,89 + b2 Log Ki,89 + b3 Log Si,89 + b4 Log Li,89 + e89 (3c) } \\
& \log \text { Qi,90 = b0 + b1 Log Ci,90 + b2 Log Ki,90 + b3 Log Si,90 + b4 Log Li,90 + e90 (3d) } \\
& \log \mathrm{Qi}, 91=\text { b0 + b1 Log Ci,91 + b2 Log Ki,91 + b3 Log Si,91 + b4 Log Li,91 + e91 (3e) }
\end{aligned}
$$

While each individual equation is based on a cross-section of the data, by constraining the coefficients on each factor to be equivalent in different years, time series variation in the data will also be reflected in the estimates of the system as a whole. In fact, under the assumption that the error terms in each equation are independently and identically distributed, estimating this system of equations is equivalent to pooling the data and estimating the parameters by ordinary least squares (OLS). However, it is likely that the variance 
of the error term varies across years, and that there is some correlation between the error terms across years. It is therefore possible to get more efficient estimates of the parameters by using the technique of Iterated Seemingly Unrelated Regressions (ISUR). [13]

As equations (3a) - (3e) are written, we have imposed the usual restriction that the parameters are equal across the sample, which allows the most precise estimates of the parameter values. We can also allow some or all of the parameters to vary over time or by firm characteristics, although this additional information is generally obtained at the expense of lowering the precision of the estimates. We will explore some of these alternative specifications in the results section; however, the main results of this paper are based on the system of equations shown in (3a)-(3e).

\subsection{Data Sources and Variable Construction}

This study employs a unique data set on IS spending by large U.S. firms which was compiled by International Data Group (IDG). The information is collected in an annual survey of IS managers at large firms [14]that has been conducted since 1987. Respondents are asked to provide the market value of central processors (mainframes, minicomputers, supercomputers) used by the firm in the U.S., the total central IS budget, the percentage of the IS budget devoted to labor expenses, the number of PCs and terminals in use, and other IT related information.

Since the names of the firms are known and most of them are publicly traded, the IS spending information from the IDG survey could be matched to Compustat II [15] to obtain measures of output, capital investment, expenses, number of employees and industry classification. In addition, these data were also combined with price deflators for output, capital, employment costs, expenses and IT capital.

There is some discretion as to how the years are matched between the survey and Compustat. The survey is completed at the end of the year for data on the following year. Since we are primarily interested in the value of computer capital stock, and the survey is timed to be completed by the beginning of the new fiscal year, we interpret the survey data as a beginning of period value, which we then match to the end of year data on Compustat (for the previous period). This also allows us to make maximum use of the survey data and is the same approach used by IDG for their reports based on these data (e.g. Maglitta and Sullivan-Trainor, 1991).

IDG reports the "market value of central processors" (supercomputers, mainframes and minicomputers) but only the total number of "PCs and terminals". Therefore, the variable for COMPUTER CAPITAL was obtained by adding the "market value of central processors" to an estimate of the value of PCs and terminals, which was computed by multiplying the weighted average value for PCs and terminals by the number of PCs and terminals. [16] This approach yields roughly equal values, in aggregate, for central processors (\$33.0 Bn) as for PCs and terminals (\$30.4 Bn) in 1991. These values corroborated by a separate survey by IDG (IDC, 1991) which tabulates shipments of computer equipment by category. This aggregate computer capital is then deflated by the computer systems deflator reported in Gordon (1993).

The variables for IS STAFF, NON-IS LABOR AND EXPENSE and OUTPUT were computed by multiplying the relevant quantity from the IDG survey or Compustat by a price deflator. IS STAFF was computed by multiplying the IS Budget figure from the IDC survey by the "percentage of the IS budget devoted to labor expenses...", and deflating this figure. NON-IS LABOR AND EXPENSE was computed by deflating total expense and subtracting deflated IS STAFF from this value. Thus, all the expenses of a firm are allocated to either IS STAFF or NON-IS LABOR AND EXPENSE.

Total capital for each firm was computed from book value of capital stock, adjusted for inflation by assuming that all investment was made at an calculated average age (total depreciation/current depreciation) of the capital stock. [17]From this total capital figure, we subtract the deflated value of 
COMPUTER CAPITAL to get NON-COMPUTER CAPITAL. Thus, all capital of a firm is allocated to either COMPUTER CAPITAL or NON-COMPUTER CAPITAL. The approach to constructing total capital follows the methods used by other authors who have studied the rate of return to specific production factors using a similar methodology (Hall, 1990; Mairesse \& Hall, 1993).

The firms in this sample are quite large. Their average sales were nearly $\$ 6.2$ billion in 1991. In many other respects, they are fairly representative of the US economy as a whole. For instance, their computer capital stock averages just over $2 \%$ of total sales, or about $\$ 216$ million, which is consistent with the capital flow tables for the US economy published by the Bureau of Economic Analysis. Similarly, the average IS budget as a share of sales was very close to the figure reported in a distinct survey by CSC/Index. A summary of the sources, construction procedure and deflator for each variable are provided in Table 1, and sample statistics are shown in Tables $2 \mathrm{a}$ and $2 \mathrm{~b}$.

\subsection{Potential Data Problems}

There are a number of possible errors in the data, either as a result of errors in source data or inaccuracies introduced by the data construction methods employed. First, the IDG data on IS spending are largely self-reported and therefore the accuracy depends on the diligence of the respondents. Some data elements require some degree of judgment -- particularly the market value of central processors and the total number of PCs and terminals. Also, not all companies responded to the survey, and even those that did respond in one year may not have responded in every other year. This may result in sample selection bias. For instance, high performing firms (or perhaps low performing firms) may have been more interested in participating to the survey. Fortunately, most of the firms in the target group did respond and, as discussed above, descriptive statistics for the sample appear to be broadly consistent with data from other sources.

However, the effect of the potential errors discussed above will probably be small. The information is intended to be published and therefore the participants have the incentive to diligently respond to the survey, and we have checked the aggregate values against other independent sources. We used different, independent source (Compustat) for our performance measures and for our IT variables, making it difficulty to "game" the survey. We also examined whether the performance of the firms in our sample (as measured by return on equity (ROE)) differ from the population of Fortune 500 Manufacturing and Fortune 500 Service firms. Our results indicate that there are no statistically significant differences between Fortune 500 firms in our sample and those that are not ( $t$-stat $=0.7)$, which suggests that our sample is not disproportionately comprised of "good" or "bad" firms. However, since the sampling method targets the largest of the Fortune 500 firms, the average firm in our sample is roughly twice as large as the average Fortune 500 firm. Finally, the response rate of the sample is relatively high at over $75 \%$, suggesting that firms are not selectively participating. These factors suggest that sample selection bias is not driving the results.

Second, there are a number of reasons why IS STAFF and COMPUTER CAPITAL may be understated, although by construction these errors do not reduce total capital and total expense for the firm. The survey is restricted to central IS spending in the U.S. plus PCs and terminals both inside and outside the central department. Some firms may have significant expenditures on information systems outside the central department or outside the U.S. In addition, the narrow definitions of IS spending employed in this study may exclude significant costs that could be legitimately counted as COMPUTER CAPITAL such as software and communication networks. Furthermore, by including only the labor portion of IS expenses in IS STAFF as a separate variable (in order to prevent double counting of capital expenditure), other parts of the IS budget are left in the NON-IS LABOR AND EXPENSE category. The effects of these problems on the final results are discussed in the Results section.

A third area of potential inaccuracy comes from the price deflators. Numerous authors (Baily \& Gordon, 1988; Siegel \& Griliches, 1991) have criticized the current methods employed by the BEA for 
constructing industry-level price deflators. It has been argued that these methods fail to fully account for quality change or other intangible improvements. If consumer purchases are in part affected by intangible quality improvements, the use of firm level data should provide some improvement, because firms which provide quality improvement will have higher sales and can be directly compared to firms in the same industry.

Finally, the measurement of OUTPUT and COMPUTER CAPITAL input in certain service industries appeared particularly troublesome. For financial services, we found that OUTPUT was poorly predicted in our model, presumably because of problems in defining and quantifying the output of financial institutions. [18]In the telecommunications industry, it has been argued (Popkin, 1992) that many of the productivity gains have come from very large investments in computer-based telephone switching gear, which is primarily classified as communications equipment and not COMPUTER CAPITAL, although it may be highly correlated with measured computer capital. We therefore excluded all firms in the financial services industries (SIC60 - SIC69), and telecommunications (SIC48). [19]

\section{RESULTS}

\subsection{Basic results}

The basic estimates for this study are obtained by estimating the system of equations (3a)- (3e) by ISUR (see section 2.2). Note that we allow the intercept term to vary across sectors and years.

As reported in column 1 of Table 3, our estimate of b1 indicates that COMPUTER CAPITAL is correlated with a statistically significant increase in OUTPUT. Specifically, we estimate that the elasticity of output for COMPUTER CAPITAL is 0.0169 when all the other input are held constant. Because COMPUTER CAPITAL accounted for an average of $2.09 \%$ of the value of output each year, this implies a gross ROI (increase in dollar output per dollar of capital stock ) for COMPUTER CAPITAL of approximately 81\% per year. [20] In other words, for every additional dollar of computer capital stock that a firm has, its output will increase by 81 cents per year on the margin. [21]

The estimate for the output elasticity for IS STAFF was 0.0178, which indicates that each dollar spent here is associated with a marginal increase in OUTPUT of \$2.62. The surprisingly high return to information systems labor may reflect systematic differences in human capital, [22] since IS staff are likely to have more education than other workers. The high return is certainly consistent with Krueger's (1991) finding that workers who use computers are paid a wage premium.

The above estimates strongly support hypothesis H1, that the contribution of IT is positive. The t-statistics for our estimates of the elasticity of COMPUTER CAPITAL and IS STAFF are 3.92 and 3.38, respectively, so we can reject the null hypothesis of zero contribution of IT at the 0.001 (two-tailed) confidence level for both. We can also reject the joint hypothesis that they are both equal to zero $(\mathrm{c} 2(2)=43.9, \mathrm{p}<.0001)$.

To assess $\mathrm{H} 2$ (that the contribution of IT is greater than its cost) it is necessary to estimate the cost of COMPUTER CAPITAL and IS STAFF. After these costs are subtracted from the gross benefits reported above, we can then assess whether the remaining "net" benefits are positive. Because IS STAFF is a flow variable, calculating net benefits is straightforward: a dollar of IS STAFF costs one dollar, so the gross returns of $\$ 2.62$ imply net returns of $\$ 1.62$. For IS STAFF, we can reject the null hypothesis that the returns equal costs in favor of the hypothesis that returns exceed costs at the .05 confidence level $(\mathrm{c} 2(1)=4.4, \mathrm{p}<.035)$.

Assessing H2 for COMPUTER CAPITAL, which is a stock variable, requires that we determine how much of the capital stock is "used up" each year and must be replaced just to return to the level at the beginning of the year. This is done by multiplying the annual depreciation [23] rate for computers by the 
capital stock in place. According to the Bureau of Economic Analysis, the average service life of "Office, Computing and Accounting Machinery" is seven years (Bureau of Economic Analysis, 1987). If a seven year service life for computer capital is assumed, then the above gross returns should be reduced by subtracting just over $14 \%$ per year, so that after seven years the capital stock will be fully replaced. This procedure yields a net return of $67 \%$. However, a more conservative assumption is that COMPUTER CAPITAL (in particular PCs) could have an average service life as short as 3 years, which implies that the net rate of return should be reduced by $33 \%$. This would yield a net ROI estimate of $48 \%$. In either case, we can reject the null hypothesis that the net marginal returns to computers are zero $(p<.01)$. [24]

An alternative approach to assessing $\mathrm{H} 2$ is to consider the opportunity cost of investing in COMPUTER CAPITAL or IS STAFF. A dollar spent in either of these areas could have generated a gross return of over $6 \%$ if it had instead been spent on NON-COMPUTER CAPITAL or a net return of $7 \%$ if it were spent on OTHER LABOR AND EXPENSE. This suggests that the net benefits were not positive unless they exceeded these returns by a statistically significant margin.

As shown in Table 6, we can reject the hypothesis that the net ROI for COMPUTER CAPITAL is equal to the ROI for NON-COMPUTER CAPITAL, assuming a service life of as little as 3 years for COMPUTER CAPITAL (and none in NON-COMPUTER CAPITAL) at the .05 confidence level. Similarly, we can reject the hypothesis that IS STAFF generates the same returns as spending on OTHER LABOR AND EXPENSE $(p<.05)$.

Our confidence in the regression taken as a whole is increased by the fact that the estimated output elasticities for the other factors of production were all positive and each was consistent not only with economic theory (i.e. they imply a real rate of return on non-IT factors of 6\%-7\%), but also with estimates of other researchers working with similar data (e.g. Hall, 1993; Loveman, 1994). Furthermore, the elasticities summed to just over one, implying constant or slightly increasing returns to scale overall, which is consistent with the estimates of aggregate production functions by other researchers (Berndt, 1991). The R2 hovered around 99\%, indicating that our independent variables could "explain" most of the variance in output.

Taken together, our results suggest that during the 1987-1991 time period, firms could have created more value if they had spent more on computer capital and labor and less on non-computer capital and labor than they actually did. In the conclusion section, we discuss some reasons why managers may have made decisions which, with the benefit of hindsight, appear to have been sub-optimal. First, however, we will further analyze the robustness of our results.

\subsection{What factors affect the rates of return for computers?}

The estimates described above were based on the assumption that the parameters did not vary over time, in different sectors, or across different subsamples of firms. Therefore, they should be interpreted only as overall averages. However, by using the multiple equations approach, it is also possible to address questions like: "Has the return to computers been consistently high, or did it vary over time?" and "Have some sectors of the economy had more success in using computers?" We respond to these questions by allowing the parameters to vary by year or by sector.

Economic theory predicts that managers will increase investments in any inputs that achieve higher than normal returns, and that as investment increases, marginal rates of return eventually fall to "normal" levels. This pattern is supported by our findings for COMPUTER CAPITAL, which exhibited higher levels of investment (Figure 2) and lower returns over time (Figure 3). We find that the rates of return are fairly consistent over the period 1987-1989 and then drop in 1990-1991. We can reject the null hypothesis of equality of returns over time in the full sample $(\mathrm{c} 2(4)=11.2, \mathrm{p}<.02)$. However, even at the end of the period, the returns to COMPUTER CAPITAL still exceed the returns to NON-COMPUTER CAPITAL. 
However, these results should be interpreted with caution since the composition of the sample changes from year to year and 1991 was a recession year. [25]

Roach (1987) has argued that the service sector uses computers much less efficiently than manufacturing and points to aggregate statistics which report higher overall productivity growth for manufacturing than for services. Others have argued that aggregate output in the service sector is poorly measured and this is the cause of the apparent shortfall of productivity in this sector (Griliches, 1992). Our data enable us to estimate the contribution of computers to sales at the firm level, without relying on aggregate data.

The returns on COMPUTER CAPITAL across sectors are present in Figure 4. The rate of return (ignoring the mining sector which includes only 10 firms and has a large standard error) varies from $10 \%$ in transportation and utilities to $127 \%$ in durable manufacturing. The high returns in the two manufacturing sectors may be due to greater competition, especially from international sources, or better measurability of the inputs and outputs in these sectors. While there have been some suggestions that reorganizing service processes around a "factory" model would help achieve comparable results in services, we cannot confirm that the differences in measured returns are due to fundamental differences, or simply "noise" in the data. Although the returns to computers in durable and non-durable manufacturing are as high or higher than the returns in any other sector, we are unable to reject the hypothesis that these rates of return are the same across most sectors due to the large standard errors on the coefficient estimates (without mining, c2(4)=6.6, $\mathrm{p}<.16)$.

A second area that can be addressed by our data and method is technology strategy. We have already shown that firms with more computer capital will, ceteris paribus, have higher sales than firms with proportionately less computer capital, but do the types of computer equipment purchased make a difference? We have data on two categories of equipment: 1) central processors, such as mainframes, and 2) PCs and terminals. For this analysis, we divide the sample into three groups based on the ratio of central processor value to PCs and terminals. We find that the rate of return is highest for firms using a more balanced mix of PCs and mainframes (Table 4), and lower for firms at either extreme. One interpretation of this finding is that an IS strategy which relies too heavily on one category of equipment will be less effective than a more even-handed approach which allows a better "division of labor".

\subsection{Sensitivity Analysis and Possible Biases - Econometric Issues}

Our estimates of the return to COMPUTER CAPITAL required that a number of assumptions be made about the econometric specification and the construction of the data set. This section and the following section explore the validity of our assumptions and generally finds that the results are robust.

The primary econometric assumption required for ISUR to produce unbiased estimates of both the parameters and the standard errors are similar to those for OLS: the error term must be uncorrelated with the regressors (inputs) and homoskedastic in the cross section. [26] ISUR implicitly corrects for serial correlation and heteroskedasticity over time in our formulation, so that additional restrictions on the error structure are not necessary. Nonetheless, we computed single-year OLS estimates both with and without heteroskedasticity-consistent standard errors [27] to examine whether heteroskedasticity is an issue for the cross-section. The standard error estimates were within $10-20 \%$ of each other, indicating that heteroskedasticity does not appear to be a problem. To test normality of the error terms, we computed and plotted residuals from the basic specification, and found them to be roughly normally distributed. It should be noted that even if these assumptions were violated, the coefficient estimates (even for OLS) would still be unbiased and consistent, and therefore represent accurate measures of the contribution of IT.

However, the third assumption, that the error term is uncorrelated with the inputs, is potentially an issue. One way in which this assumption could be violated is if the causality is reversed: instead of increases in 
purchases of inputs (e.g. computers) leading to higher output, an increase in output could lead to further investment (for example, a firm spends the proceeds from an unexpected increase in demand on more computer equipment). In this case, the assumptions for ISUR are violated since the inputs are not predetermined, and therefore the error term is likely to be correlated with them. The assumption could also be violated if the input variables are measured with error [28] (see (Kmenta, 1986) for a complete discussion).

Regardless of the source of the error, it is possible to correct for the potential bias using instrumental variables methods, or two-stage least squares (2SLS). This method employs instrumental variables to filter out the endogenous variation and error in the variables, which then allows consistent estimation of the parameters. We use once-lagged values of variables as instruments, since by definition they cannot be associated with unanticipated shocks in the dependent variable in the following year. [29] Table 5 reports a comparison of pooled OLS estimates with 2SLS estimates and shows that the coefficient estimates are similar although somewhat higher for COMPUTER CAPITAL and lower for IS STAFF. In both cases the standard errors were substantially larger, as is expected when instrumental variables are used. Using a Hausman specification test, we cannot reject the null hypothesis that the error term is uncorrelated with the regressors (see bottom of Table 5 for test statistics), and therefore accept our initial specification.

All the results discussed previously assumed that the production function was of the Cobb-Douglas form. While this approach is well grounded in previous research, further insight into the role of computer capital may be gained by allowing a more flexible functional form such as the translog. [30]

When we estimated a translog production function, the calculated value of the COMPUTER CAPITAL elasticity was .0108, [31] which is comparable to the Cobb-Douglas estimate, although the standard error was much higher, presumably due to the large number of additional parameters which had to be estimated. [32] This lends support to the assertion made by Griliches (1979) that the choice of functional form is not critical in the estimation of output elasticities.

\subsection{Sensitivity Analysis and Possible Biases - Data Issues}

To further explore the robustness of our results, we examined impact of the possible data errors discussed in section 2.4 that can be tested: 1) error in the valuation of PCs and terminals, 2) understatement of computer capital, and 3) errors in the price deflators.

To assess the sensitivity of the results to the assumptions of the value of PCs and terminals, we recalculated the basic regressions varying the assumed average PC and terminal value from $\$ 0$ to $\$ 6 \mathrm{~K}$. Note that as the assumed value of PCs and terminals increases, the increase in COMPUTER CAPITAL will be matched by an equal decrease in NON-COMPUTER CAPITAL, which is calculated as a residual. Interestingly, as shown in Figure 5, the return to COMPUTER CAPITAL in the basic regression is not very sensitive to the assumed value of PCs and terminals, ranging from $77 \%$ if they are not counted to $59 \%$ if PCs and terminals are counted at $\$ 6 \mathrm{~K}$. The reason the return rises at first when PCs and terminals are counted as part of COMPUTER CAPITAL is presumably that firms with large investments in PCs and terminals have higher output than similar firms without such investments. Initially, this increased output raises the estimated elasticity of COMPUTER CAPITAL by more than the assumed costs of PCs and terminals, and therefore the estimated return to computers increases.

Our estimates of the return to COMPUTER CAPITAL or IS STAFF may be overstated since, as discussed in section 2.3, the true cost of computer capital and IS staff may be understated. If the hidden IS costs do not show up elsewhere in the firm, then the effect on the estimated returns is dependent on how closely correlated these costs are to our measured COMPUTER CAPITAL. If they are uncorrelated, our estimate for the elasticity and the return to COMPUTER CAPITAL is unbiased. If the missing costs are perfectly correlated with the observed costs, then, because of the logarithmic form of our specification, they will 
result only in a multiplicative scaling of the variables, and the estimated elasticities and the estimated standard error will be unchanged. [33] For the same reason, the sign and statistical significance of our results for the returns to COMPUTER CAPITAL and IS STAFF will be also unaffected. However, the denominator used for the ROI calculations will be affected by increasing computer capital so the estimated ROI will be proportionately lower or higher. For instance, if the hidden costs lead to a doubling of the true costs of computer capital, then the true ROI would fall from $81 \%$ to just over $40 \%$. Finally, if the hidden costs are negatively correlated with the observed costs, then the true returns would be higher than our estimates.

Another possibility is that the hidden IS capital expenses (e.g. software) show up elsewhere, such as in the NON-IS LABOR AND EXPENSE category. To estimate the potential impact of these omissions, we estimate the potential size of the omitted misclassified IS capital relative to COMPUTER CAPITAL using data from another IDG survey (IDC, 1991) on aggregate IS expenditures, including software as well as hardware. To derive a reasonable lower bound on the returns to COMPUTER CAPITAL, we assume that the misclassified IS capital had an average service life of three years, and further make the worst-case assumption of perfect correlation between misclassified IS capital and COMPUTER CAPITAL (and reduce proportionally the amount of NON-IS LABOR AND EXPENSE). In this scenario, our estimates for the amount of COMPUTER CAPITAL in firms roughly doubles, yet the rates of return are little unchanged from the basic analysis that does not include misclassified IS capital (68\% vs. 81\%). This surprising result appears to be due to the fact that the return on NON-IS LABOR AND EXPENSE is at least as high as the return on COMPUTER CAPITAL, so moving costs from one category to another does not change overall returns much.

It should be noted that the definition of COMPUTER CAPITAL used in this study was fairly narrow and did not include items such as telecommunications equipment, scientific instruments, networking equipment. The findings should be interpreted accordingly and do not necessarily apply to broader definitions of IT.

One final contribution to error is the understatement of output due to errors in the price deflators. While it is difficult to directly correct for this problem, we estimated the basic equations year by year, so that errors in the relative deflators would have no impact on the elasticity estimates. The estimated returns ranged $109 \%$ to $197 \%$ versus $81 \%$ when all five years were estimated simultaneously. The standard error on the estimates was significantly higher for all estimates, which can account for the greater range of estimates. Overall, this suggests that our basic findings are not a result of the assumed price deflators. However, if the price deflators systematically underestimate the value of intangible product change over time or between firms, our measure of output will be understated, implying that the actual return for computer capital is higher than our estimates.

On balance, we may have underestimated both IS input and final output. The directions of the resulting biases go in opposite directions, but under reasonable assumptions they do not appear to obviate the basic finding that the return on IS capital and labor spending is statistically significant and exceeds that of other types of capital and labor.

\section{DISCUSSION}

\subsection{Comparison with earlier research}

Although we found that computer capital and IS labor increase output significantly, several other studies have failed to find evidence that IT increases output. Because the models we used were similar to those used by several previous researchers, we attribute our different findings primarily to the larger and more recent data set we used. Specifically, there are at least three reasons why our results may differ from previous results. 
First, we examined a later time period, (1987-1991), than did Loveman (1978-1982), Barua et al. (1978-1982) or Berndt \& Morrison (1968-1986). The massive build-up of computer capital is a relatively recent phenomenon. Indeed, the delivered amount of computer power in the companies in our sample is likely to be at least an order of magnitude greater than that in comparable firms from the period studied by the other authors. Brynjolfsson (1993) argues that even if the ROI of IT were twice that of non-IT capital, its impact on output in the 1970s or early 1980s would not have been large enough to be detected by conventional estimation procedures. Furthermore, the changes in business processes needed to realize the benefits of IT may have taken some time to implement, so it is possible that the actual returns from investments in computers were initially fairly low. In particular, computers may have initially created organizational slack which was only recently eliminated, perhaps hastened by the increased attention engendered by earlier studies that indicated a potential productivity shortfall and suggestions that "to computerize the office, you have to reinvent the office" (Thurow, 1990). Apparently, an analogous period of organizational redesign was necessary to unleash the benefits of electric motors (David, 1989).

A pattern of low initial returns is also consistent with the strategy for optimal investment in the presence of learning-by-using: short-term returns should initially be lower than returns for other capital, but subsequently rise to exceed the returns to other capital, compensating for the "investment" in learning (Lester \& McCabe, 1993). Under this interpretation, our high estimates of computer ROI indicate that businesses are beginning to reap rewards from the experimentation and learning phase in the early 1980s.

Second, we were able to use different and more detailed firm-level data than had been available before. We argue that the effects of computers in increasing variety, quality or other intangibles are more likely to be detected in firm level data than in the aggregate data. Unfortunately, all such data, including ours, is likely to include data errors. It is possible that the data errors in our sample happened to be more favorable (or less unfavorable) to computers than those in other samples. We attempted to minimize the influence of data errors by cross-checking with other data sources, eliminating outliers, and examining the robustness of the results to different subsamples and specifications. In addition, the large size of our sample, should, by the law of large numbers, mitigate the influence of random disturbances. Indeed, the precision of our estimates was generally much higher than those of previous studies; the statistical significance of our estimates owes as much to the tighter confidence bounds as to higher point estimates.

Third, our sample consisted entirely of relatively large "Fortune 500" firms. It is possible that the high IS contribution we find is limited to these larger firms. However, an earlier study, (Brynjolfsson, Malone, Gurbaxani \& Kambil, 1994), found evidence that smaller firms may benefit disproportionately from investments in information technology. In any event, because firms in the sample accounted for such a large share of the total US output, the economic relevance of our findings is not heavily dependent on extrapolation of the results to firms outside of the sample.

\subsection{Managerial Implications}

If the spending on computers is correlated with significantly higher returns than spending on other types of capital, it does not necessarily follow that companies should increase spending on computers. The firms with high returns and high levels of computer investment may differ systematically from the low performers in ways that cannot be rectified simply by increasing spending. For instance, recent economic theory has suggested that "modern manufacturing", involving high intensity of computer usage, may require a radical change in organization (Milgrom \& Roberts, 1990). This possibility is emphasized in numerous management books and articles (see, e.g. Malone \& Rockart, 1991; Scott Morton, 1991) and supported in our discussions with managers, both at their firms and during a workshop on IT and Productivity attended by approximately 30 industry representatives. [34]

Furthermore, our results showing a high gross rate of return may be indicative of the differences between computer investment and other types of investment. For instance, managers may perceive IS investment 
as riskier than other investments, and therefore require higher expected returns to compensate for the increased risk. Finally, IS is often cited as an enabling technology which does not just produce productivity improvements for individuals, but provides a vast advantage by facilitating business process redesign or improving the ability of groups to work together. In this sense, our results may be indicative of the substantial payoffs to reengineering and other recent business innovations.

\section{CONCLUSION}

We examined data which included over 1000 observations on output and several inputs at the firm level for 1987-1991. The firms in our sample had aggregate sales of over \$1.8 trillion in 1991 and thus account for a substantional share of the U.S. economy. We tested a broad variety of specifications, examined several different subsamples of the data, and validated the assumptions of our econometric procedures to the extent possible.

The data indicate that COMPUTER CAPITAL and IS STAFF spending contribute significantly to firm level OUTPUT. Furthermore, we were able to reject the hypothesis that the (gross) ROI for COMPUTER CAPITAL was equal to the ROI for NON-COMPUTER CAPITAL in favor of the hypothesis that the ROI for COMPUTER CAPITAL was higher. Even when we adjusted for depreciation using the BEA 7-year service life assumption for COMPUTER CAPITAL, the differences in return are still significant. The basic result that COMPUTER CAPITAL and IS STAFF contribute significantly to total output are robust to reasonable assumptions about measurement error due to exclusion of unmeasured factors.

There are a number of other directions in which this work could be extended. In the current formulation, it is difficult to make direct comparisons between firms in different industries because the definitions of "output" vary. An alternative dependent variable which can be estimated using production functions is value added. This approach should treat firms in a more comparable way, allowing greater precision in estimating the effects of IS spending, and therefore enabling more complex production function relationships to be examined. For instance, comparisons of retail stores with manufacturing firms will be more accurate when value-added is used as the dependent variable. It would also be worthwhile to investigate the role of other variables, such as research and development expenditures, which might be associated with the advancement of technology in general, and IT in particular. One recent study (Dunne, 1993) suggested that firms which invest heavily in R\&D are also most innovative in their use of IT.

Although our approach allowed us to infer the value created by intangibles like product variety by looking at changes in the revenues at the firm level, more direct approaches might also be promising. For instance, other variables can be collected to see whether computer productivity is systematically related to characteristics such as variety of product line, or the average defect rate in their output.

Finally, the type of extension which is likely to have the greatest impact on practice is further analysis of the factors which differentiate firms with high returns to IT from low performers. For instance, is the current "downsizing" of firms leading to higher IT productivity? Are the firms that have undertaken substantial "reengineering efforts" also the ones with the highest returns? Since this study has presented evidence that the computer "productivity paradox" is a thing of the past, it seems appropriate that the next round of work should focus on identifying the strategies which have led to large IT productivity.

\section{TABLES AND FIGURES}

Figure 1: Comparison of Gross Return on Investment 


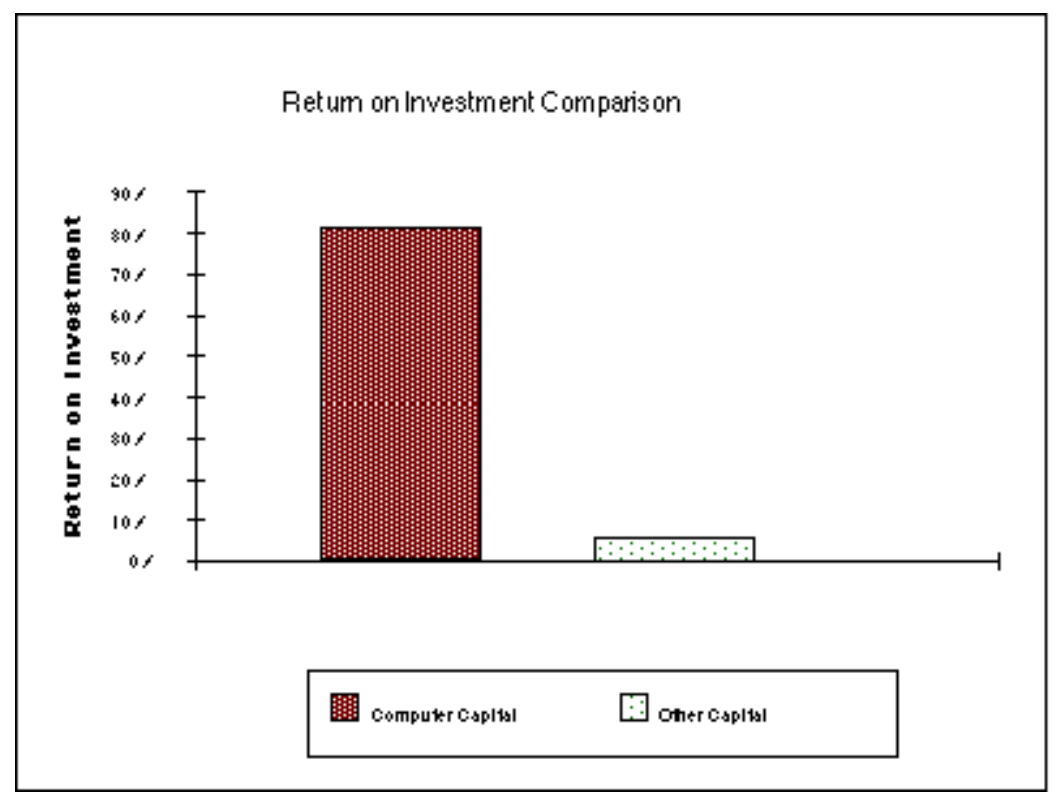

Figure 2: Changes in IT Inputs over Time

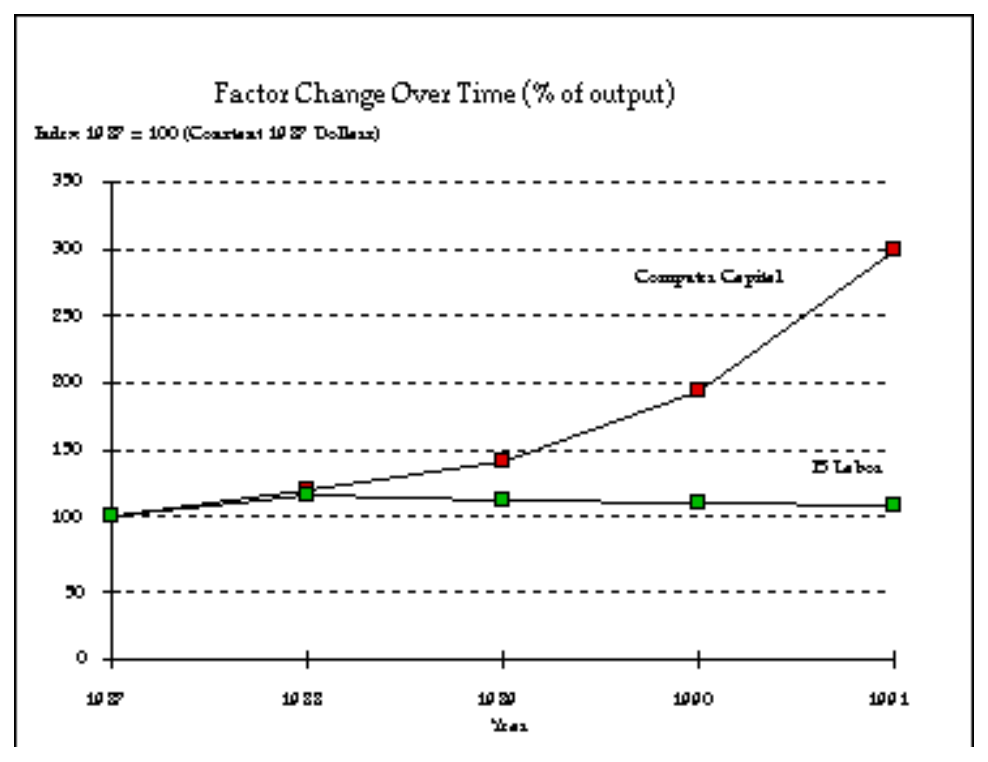

Figure 3: Gross Return on Investment Over Time - Manufacturing \& Services

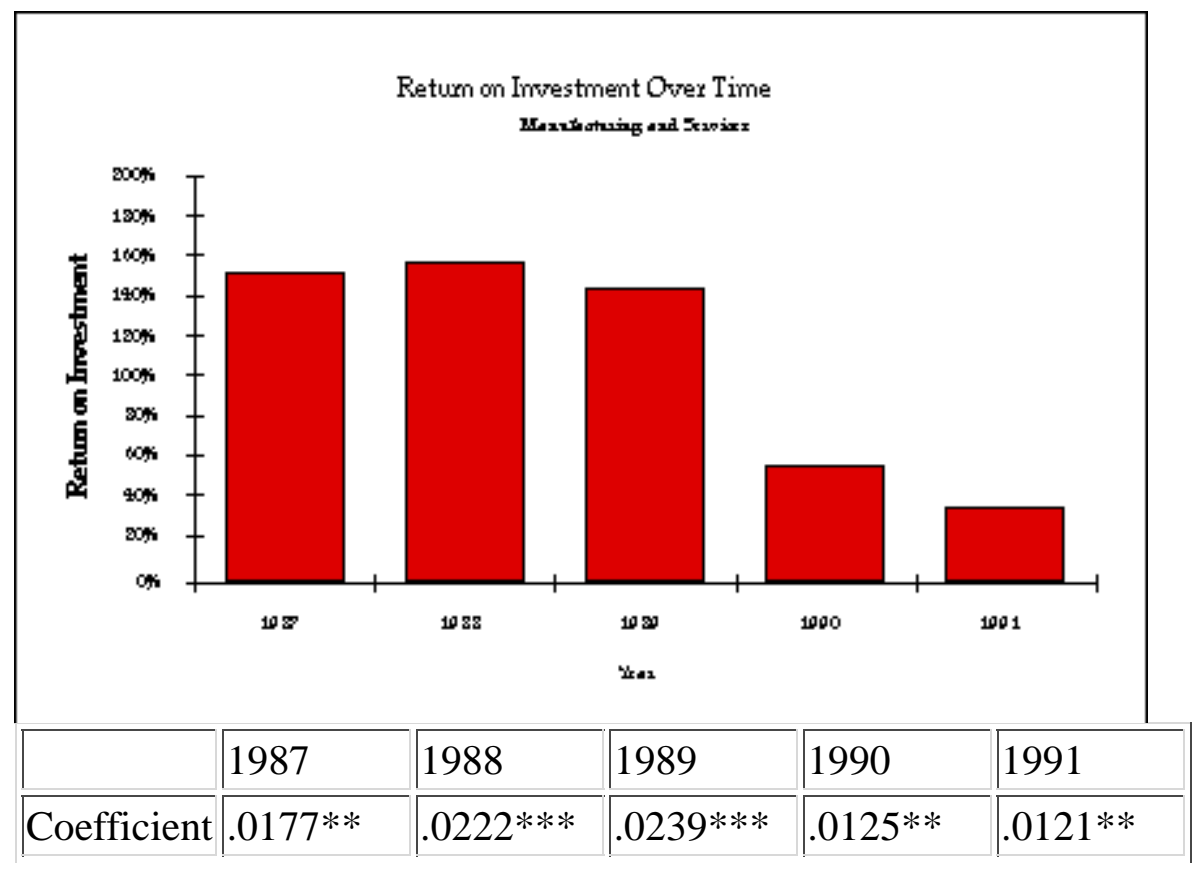




\begin{tabular}{|l|l|l|l|l|l|}
\hline Std. Error & $(.00721)$ & $(.00646)$ & $(.00657)$ & $(.00574)$ & $(.00594)$ \\
\hline $\mathrm{N}$ & 135 & 133 & 274 & 286 & 293 \\
\hline
\end{tabular}

Key: $* * *-\mathrm{p}<.01, * *-\mathrm{p}<.05, *-\mathrm{p}<.1$, standard errors in parenthesis

Figure 4: Gross Return on Investment by Sector

Retum on Irvestment by Sector

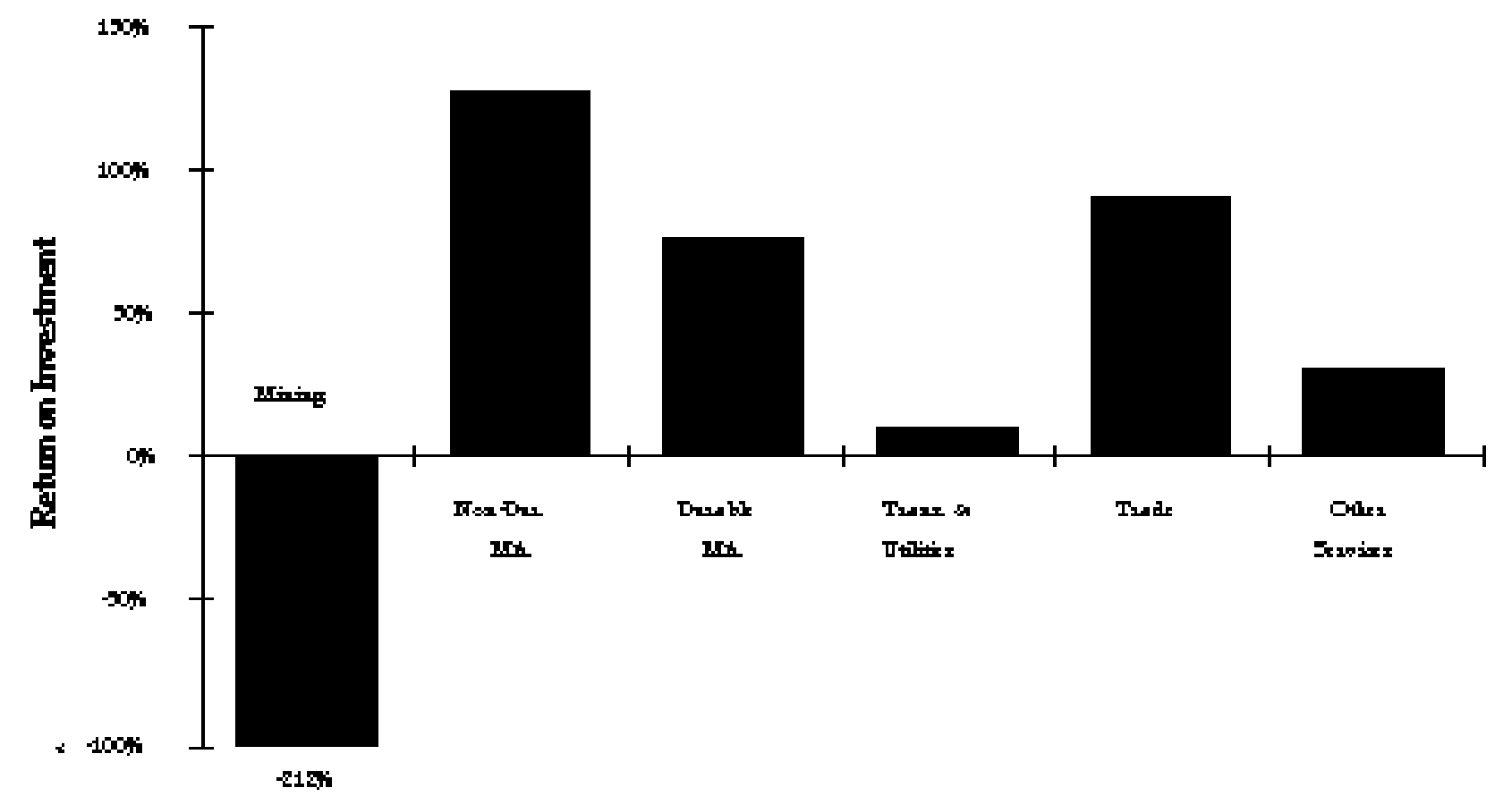

\begin{tabular}{|c|c|c|c|c|c|c|}
\hline & Mining & $\begin{array}{l}\text { Non-Dur. } \\
\text { Mfr. }\end{array}$ & $\begin{array}{c}\text { Durable } \\
\text { Mfr. }\end{array}$ & $\begin{array}{l}\text { Trans. \& } \\
\text { Utilities }\end{array}$ & Trade & $\begin{array}{l}\text { Other } \\
\text { Service }\end{array}$ \\
\hline Coefficient & -.0286 & $.0122 *$ & $.0348 * * *$ & .00227 & .0129 & .0153 \\
\hline Std. Error & $(.0218)$ & $(.00691)$ & $(.00678)$ & (.0111) & $(.00921)$ & $(.0354)$ \\
\hline N (total) & 28 & 414 & 360 & 171 & 123 & 25 \\
\hline
\end{tabular}

Key: $* * *-\mathrm{p}<.01, * *-\mathrm{p}<.05, *-\mathrm{p}<.1$, standard errors in parenthesis

Figure 5: Gross Return on Investment for Computer Capital with different PC value assumptions 


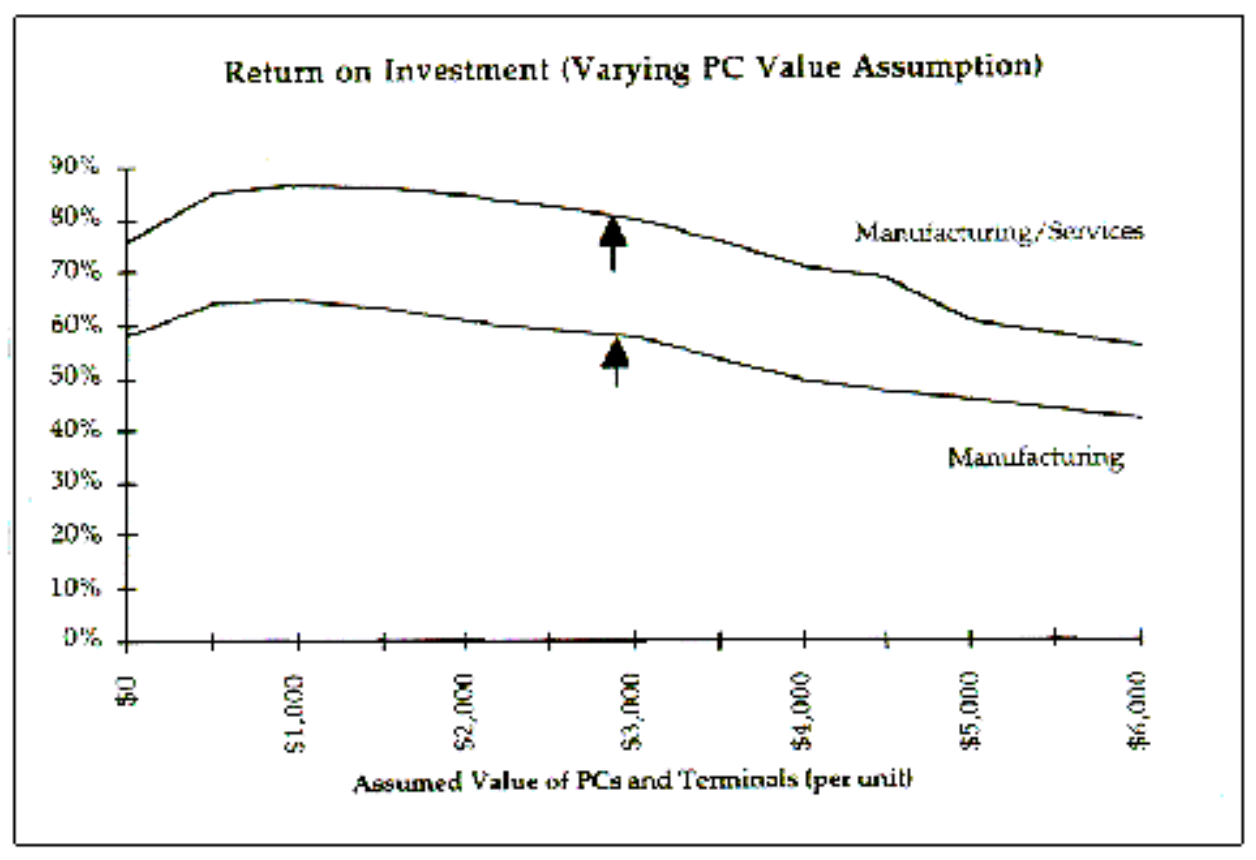

Table 1: Data Sources, Construction Procedures, and Deflators

\begin{tabular}{|c|c|c|c|}
\hline Series & Source & $\begin{array}{l}\text { Construction } \\
\text { Procedure }\end{array}$ & Deflator \\
\hline $\begin{array}{l}\text { Computer } \\
\text { Capital }\end{array}$ & $\begin{array}{l}\text { IDG } \\
\text { Survey }\end{array}$ & $\begin{array}{l}\text { "Market Value of } \\
\text { Central Processors" } \\
\text { converted to constant } \\
1987 \text { dollars, plus the } \\
\text { total number of PCs } \\
\text { and terminals } \\
\text { multiplied by an } \\
\text { average value of a } \\
\text { PC/terminal, also } \\
\text { converted to constant } \\
1987 \text { dollars. }\end{array}$ & $\begin{array}{l}\text { Deflator for Computer } \\
\text { Systems (Gordon, } \\
\text { 1993). }\end{array}$ \\
\hline $\begin{array}{l}\text { Non- } \\
\text { Computer } \\
\text { Capital }\end{array}$ & Compustat & $\begin{array}{l}\text { Total Property, Plant } \\
\text { and Equipment } \\
\text { Investment converted } \\
\text { to constant } 1987 \\
\text { dollars. Adjusted for } \\
\text { retirements using } \\
\text { Winfrey S-3 Table (10 } \\
\text { year service life) and } \\
\text { aggregated to create } \\
\text { capital stock. } \\
\text { Computer capital as } \\
\text { calculated above was } \\
\text { subtracted from this } \\
\text { result. }\end{array}$ & $\begin{array}{l}\text { GDP Implicit Deflator } \\
\text { for Fixed Investment } \\
\text { (Council of Economic } \\
\text { Advisors, 1992). }\end{array}$ \\
\hline IS Staff & $\begin{array}{l}\text { IDG } \\
\text { Survey }\end{array}$ & $\begin{array}{l}\text { Total IS Budget times } \\
\text { percentage of IS } \\
\text { Budget (by company) }\end{array}$ & $\begin{array}{l}\text { Index of Total } \\
\text { Compensation Cost } \\
\text { (Private Sector) }\end{array}$ \\
\hline
\end{tabular}




\begin{tabular}{|c|c|c|c|}
\hline & & $\begin{array}{l}\text { devoted to labor } \\
\text { expense. Converted to } \\
\text { constant } 1987 \text { dollars. }\end{array}$ & $\begin{array}{l}\text { (Council of Economic } \\
\text { Advisors, 1992). }\end{array}$ \\
\hline $\begin{array}{l}\text { Non-IS } \\
\text { Labor } \\
\text { and } \\
\text { Expense }\end{array}$ & Compustat & $\begin{array}{l}\text { Total Labor, Materials } \\
\text { and other non-interest } \\
\text { expenses converted to } \\
\text { constant } 1987 \text { dollars. } \\
\text { IS labor as calculated } \\
\text { above was subtracted } \\
\text { from this result. }\end{array}$ & $\begin{array}{l}\text { Producer Price Index } \\
\text { for Intermediate } \\
\text { Materials, Supplies and } \\
\text { Components (Council } \\
\text { of Economic Advisors, } \\
\text { 1992). }\end{array}$ \\
\hline Output & Compustat & $\begin{array}{l}\text { Total sales converted to } \\
\text { constant } 1987 \text { dollars. }\end{array}$ & $\begin{array}{l}\text { Industry Specific } \\
\text { Deflators from Gross } \\
\text { Output and Related } \\
\text { Series by Industry, BEA } \\
\text { (1977-89) where } \\
\text { available (about } 80 \% \\
\text { coverage) - extrapolated } \\
\text { for } 1991 \text { assuming } \\
\text { average inflation rate } \\
\text { from previous five } \\
\text { years. Otherwise, sector } \\
\text { level Producer Price } \\
\text { Index for Intermediate } \\
\text { Materials Supplies and } \\
\text { Components (Gorman, } \\
\text { 1992). }\end{array}$ \\
\hline
\end{tabular}

Table 2a: Summary Statistics

\section{Sample Statistics - Average over all points}

(Constant 1987 Dollars)

\begin{tabular}{|l|c|c|c|}
\hline \multirow{2}{*}{} & \multicolumn{1}{c|}{$\begin{array}{c}\text { Total \$ } \\
\text { (Annual } \\
\text { Average) }\end{array}$} & As a \% of & Per Firm \\
& Output & Average \\
\hline Output & $\$ 1,661 \mathrm{Bn}$ & $100 \%$ & $\$ 7.41 \mathrm{Bn}$ \\
\hline Computer Capital & $\$ 34.7 \mathrm{Bn}$ & $2.09 \%$ & $\$ 155 \mathrm{MM}$ \\
\hline Non-Computer Capital & $\$ 1,614 \mathrm{Bn}$ & $97.2 \%$ & $\$ 7.20 \mathrm{Bn}$ \\
\hline IS Staff & $\$ 11.3 \mathrm{Bn}$ & $0.68 \%$ & $\$ 50.4 \mathrm{MM}$ \\
\hline $\begin{array}{l}\text { Non-IS Labor and } \\
\text { Expenses }\end{array}$ & $\$ 1,384 \mathrm{Bn}$ & $83.3 \%$ & $\$ 6.17 \mathrm{Bn}$ \\
\hline $\begin{array}{l}\text { Avg. Number of } \\
\text { Companies per Year }\end{array}$ & 224 & 224 & 224 \\
\hline Total Observations & 1121 & 1121 & 1121 \\
\hline
\end{tabular}


Table 2b. Sample Composition relative to Fortune 500 Population

\begin{tabular}{|c|c|c|c|}
\hline \multicolumn{4}{|c|}{$\begin{array}{l}\text { Sample Composition } \\
\text { Number of firms }\end{array}$} \\
\hline & \begin{tabular}{|l|} 
Fortune 500 \\
Manufacturing
\end{tabular} & $\begin{array}{c}\text { Fortune } 500 \\
\text { Service }\end{array}$ & Other \\
\hline 1991 Sample & 196 & 83 & 14 \\
\hline $\begin{array}{l}\text { All Firms in } \\
\text { Compustat }\end{array}$ & 466 & 424 & n.a. \\
\hline
\end{tabular}

Table 3: Base Regressions - Coefficient Estimates and Implied Gross Rates of Return

All parameters (except year dummy) constrained to be equal across years.

\begin{tabular}{|c|c|c|}
\hline Parameter & Coefficients & Returns \\
\hline $\begin{array}{l}\beta 1 \text { (Computer } \\
\text { Capital) }\end{array}$ & $\begin{array}{l}.0169 * * * \\
(.00431)\end{array}$ & $81.0 \%$ \\
\hline $\begin{array}{l}\beta 2 \text { (Non-computer } \\
\text { Capital) }\end{array}$ & $\begin{array}{l}.0608 * * * \\
(.00466)\end{array}$ & $6.26 \%$ \\
\hline ß33 (IS Staff) & $\begin{array}{l}.0178 * * * \\
(.00526)\end{array}$ & 2.62 \\
\hline $\begin{array}{l}34 \text { (Other Labor \& } \\
\text { Exp.) }\end{array}$ & $\begin{array}{l}.883 * * * \\
(.00724)\end{array}$ & 1.07 \\
\hline Dummy Variables & $\begin{array}{l}\text { Year*** \& }^{* *} \\
\text { Sector*** }^{*}\end{array}$ & \\
\hline $\mathrm{R}^{2}(1991)$ & $97.5 \%$ & \\
\hline N (1991) & 293 & \\
\hline $\mathrm{N}$ (total) & 1121 & \\
\hline
\end{tabular}

Key: *** $-\mathrm{p}<.01, * *-\mathrm{p}<.05, *-\mathrm{p}<.1$, standard errors in parenthesis

Table 4: Split Sample Regression Results

\section{Coefficient Estimates and Rates of Return for $\beta 1,($ Computer Capital)}

Each Cell contains coefficient estimate, (standard error), ROI

\begin{tabular}{|l|l|l|l|l|}
\hline Sample Split & Highest & Middle & Lowest & Statistical \\
\hline
\end{tabular}




\begin{tabular}{|l|c|c|c|c|}
\hline Mainframes/PCs & $.0113^{* *}$ & $.0159 * * *$ & $.0117^{* *}$ & \\
Ratio & $(.00500)$ & $(.00528)$ & $(.00521)$ & Med $>($ Hi,Low $)$ \\
& $49.1 \%$ & $79.5 \%$ & $58.2 \%$ & $(\mathrm{p}<.03)$ \\
\hline
\end{tabular}

Key: $* * *-\mathrm{p}<.01, * *-\mathrm{p}<.05, *-\mathrm{p}<.1$, standard errors in parenthesis

1 - Ordering by $X^{2}$ tests of return differences. P-value shown represents null hypothesis of equality across groups.

\section{Table 5: Specification Test - Comparison of OLS and Two-Stage Least Squares}

All parameters (except year dummy) constrained to be equal across years.

\begin{tabular}{|c|c|c|}
\hline Parameter & $\begin{array}{c}\text { OLS } \\
\text { Estimates }\end{array}$ & $\begin{array}{c}\text { 2SLS } \\
\text { Estimates }\end{array}$ \\
\hline $\begin{array}{l}\beta 1 \text { (Computer } \\
\text { Capital) }\end{array}$ & $\begin{array}{l}.0284 * * * \\
(.00723)\end{array}$ & $\begin{array}{c}.0435 * * * \\
(.0126)\end{array}$ \\
\hline $\begin{array}{l}\beta 2 \text { (Non-computer } \\
\text { Capital) }\end{array}$ & $\begin{array}{l}.0489 * * * \\
(.00668)\end{array}$ & $\begin{array}{l}.0481^{* * *} \\
(.00702)\end{array}$ \\
\hline 阝3 (IS Staff) & $\begin{array}{l}.0191 * * * \\
(.00795)\end{array}$ & $\begin{array}{l}.00727 \\
(.0116)\end{array}$ \\
\hline $\begin{array}{l}\beta 4 \text { (Non-IS Labor \& } \\
\text { Exp.) }\end{array}$ & $\begin{array}{l}.881 * * * \\
(.0113)\end{array}$ & $\begin{array}{l}.879 * * * \\
(.0125)\end{array}$ \\
\hline Dummy Variables & $\begin{array}{l}\text { Year*** \& } \\
\text { Sector*** }\end{array}$ & $\begin{array}{l}\text { Year*** \& } \\
\text { Sector*** }\end{array}$ \\
\hline $\mathrm{R}^{2}$ & $98.3 \%$ & $98.3 \%$ \\
\hline $\mathrm{N}$ (total) & 702 & 702 \\
\hline $\begin{array}{l}\text { Durbin-Watson } \\
\text { Statistic }\end{array}$ & .42 & .42 \\
\hline
\end{tabular}

Key: ${ }^{* * *}-\mathrm{p}<.01,{ }^{*}-\mathrm{p}<.05,{ }^{*}-\mathrm{p}<.1$, standard errors are in parentheses

Note: OLS estimates are for sample of same firms as were available for 2SLS regression.

Hausman Test Results (instruments are lagged independent variables):

$X^{2}(4)=6.40,(\mathrm{p}<.17)$ - cannot reject exogeneity

Table 6: $X^{2}$ Tests for Differences in Rates of Return between Computer Capital and Other Capital

\begin{tabular}{|l|l|l|l|}
\hline $\begin{array}{l}\text { Return Difference } \\
\text { Tests }\end{array}$ & & & \\
\hline & Return & $X^{2}$ Statistic & Significance \\
\hline
\end{tabular}




\begin{tabular}{|l|c|c|c|} 
Gross Return & $81 \%$ & 15.5 & $\mathrm{p}<.0001$ \\
\hline $\begin{array}{l}\text { Net - 7 Year Service } \\
\text { Life }\end{array}$ & $67 \%$ & 10.6 & $\mathrm{p}<.0011$ \\
\hline $\begin{array}{l}\text { Net - 3 Year Service } \\
\text { Life }\end{array}$ & $48 \%$ & 5.5 & $\mathrm{p}<.0193$ \\
\hline
\end{tabular}

Key: $* * *-\mathrm{p}<.01, * *-\mathrm{p}<.05, *-\mathrm{p}<.1$, two-tailed tests

A significant test indicates that the return on computer capital is greater than the return on other capital.

\section{BIBLIOGRAPHY}

Alpar, P. and Kim, M. A Comparison of Approaches to the Measurement of IT Value. In Proceedings of the Twenty-Second Hawaii International Conference on System Science (Honolulu, HI, 1990).

Baily, M.N. and Gordon, R.J. The Productivity Slowdown, Measurement Issues, and the Explosion of Computer Power. In W. C. Brainard, \& G. L. Perry, (Eds.), Brookings Papers on Economic Activity. Washington, DC: The Brookings Institution, 1988.

Barua, A., Kriebel, C. and Mukhopadhyay, T. Information Technology and Business Value: An Analytic and Empirical Investigation . University of Texas at Austin Working Paper (May, 1991).

Belsey, D.A. Conditioning Diagnostics: Collinearity and Weak Data in Regression. J. Wiley, New York, 1991.

Berndt, E. and Griliches, Z. Price Indexes for Microcomputers: An Exploratory Study . National Bureau of Economic Research Working Paper \#3378 (1990).

Berndt, E. The Practice of Econometrics: classic and contemporary. Reading, MA: Addison-Wesley, 1991.

Berndt, E.R. and Morrison, C.J. High-Tech Capital Formation and Economic Performance in U.S. Manufacturing Industries: An Exploratory Analysis. Journal of Econometrics, (1994, in press) .

Brooke, G.M. The Economics of Information Technology: Explaining the Productivity Paradox. MIT Sloan School of Management CISR Working Paper \#238 (April, 1992).

Brynjolfsson, E. and Hitt, L. Is Information Systems Spending Productive? New Evidence and New Results. International Conference on Information Systems (Orlando, FL, 1993).

Brynjolfsson, E. The Productivity Paradox of Information Technology: Review and Assessment. Communications of the ACM (1993, in press).

Brynjolfsson, E., Malone, T., Gurbaxani, V., et al. Does Information Technology Lead to Smaller Firms? Management Science, Forthcoming (1994).

Bureau of Economic Analysis, U.S.D.O.C. Fixed Reproducible Tangible Wealth in the United States, 1925-85. Washington, D.C.: U.S. Government Printing Office, 1987.

Council of Economic Advisors (Ed.), Economic Report of the President. Washington, DC: United States Government Printing Office, 1992.

David, P.A. Computer and Dynamo: The Modern Productivity Paradox in a Not-Too-Distant Mirror. 
Stanford, CA, Center for Economic Policy Research (1989).

Dos Santos, B.L., Peffers, K.G. and Mauer, D.C. The Impact of Information Technology Investment Announcements on the Market Value of the Firm. Information Systems Research, Vol. 4, No. 1 (March 1993), pp. 1-23.

Dunne, T. Research and Development Expenditures and Computer-Based Technology Usage. University of Oklahoma Working Paper (October 1993).

Gordon, R.J. The Measurement of Durable Goods Prices. National Bureau of Economic Research. Chicago: University of Chicago Press, 1993.

Gorman, J.A. Output Deflators by Industry. Raw data provided on computer disk from Bureau of Economic Analysis (1992).

Griliches, Z. and Mairesse, J. Productivity and R\&D at the Firm Level. In Griliches, Z., (Ed.), R\&D, Patents and Productivity. National Bureau of Economic Research. Chicago: University of Chicago Press, 1984, pp. 339-374.

Griliches, Z. Issues in assessing the contribution of research and development to productivity growth. Bell Journal of Economics, Vol. 10, No. 1 (1979), pp. 92-116.

Griliches, Z. The Search for R\&D Spillovers. National Bureau of Economic Research Working Paper \#3768 (July, 1991).

Griliches, Z. Computers and Productivity: A Paradox of Substance or Measurement . National Bureau of Economic Research Working Paper (June, 1992).

Kambil, A., Henderson, J.C. and Mohsenzadeh, H. Strategic Management of Information Technology Investments: An Options Perspective. In R. D. Banker, R. J. Kauffman, \& M. A. Mahmood, Strategic Information Technology Management: Perspectives on Organizational Growth and Competitive Advantage. Harrisburg, PA: Idea Group Publishing, 1993.

Hall, B.H. New Evidence on the Impacts of Research and Development. University of California at Berkeley mimeo (May 19, 1993).

Hall, B.H. The Manufacturing Sector Master File: 1959-1987, Documentation. National Bureau of Economic Research Working Paper \#3366 (April, 1990).

Harris, S.E. and Katz, J.L. Profitability and Information Technology Capital Intensity in the Insurance Industry. In Proceedings of the Twenty-First Hawaii International Conference on System Science (1988)

International Data Corporation. U.S. Information Technology Spending Patterns, 1969-1994. IDC Special Report \#5368 (1991).

Kemerer, C.F. and Sosa, G.L. Systems Development Risks in Strategic Information Systems. Information and Software Technology, Vol. 33, No. 3, April (1991), pp. 212-223.

Kmenta, J. Elements of Econometrics. New York: Macmillan, 1986.

Krueger, A. How Computers Have Changed the Wage Structure: Evidence from Microdata, 1984-1989 .

National Bureau of Economic Research Working Paper \#3858 (October, 1991).

Lester, R.K. and McCabe, M.J. The Effect of Industrial Structure on Learning by Doing in Nuclear Power 
Plant Performance. Rand Journal of Economics, forthcoming (1993).

Loveman, G.W. An Assessment of the Productivity Impact on Information Technologies. In T. J. Allen, \& M. S. Scott Morton, Information Technology and the Corporation of the 1990s: Research Studies. MIT, 1994.

Mairesse, J. and Hall, B.H. R\&D Investment and Productivity Growth in the 1980s: A First Look at the United States and French Manufacturing Sectors. Prepared for the AEA Meetings (Anaheim, CA, 1993).

Maglitta, J. and Sullivan-Trainor, M. (Ed.), The Premier 100, Computerworld, Framingham, Massachusetts: CW Publishing, Inc., 1991.

Malone, T. and Rockart, J. Computers, Networks and the Corporation. Scientific American, Vol. 265, No. 3 (1991), pp. 128-136.

Milgrom, P. and Roberts, J. The Economics of Modern Manufacturing: Technology, Strategy, and Organization. American Economic Review, Vol. 80, No. 3 (1990).

Morrison, C.J. and Berndt, E.R. Assessing the Productivity of Information Technology Equipment in the U.S. Manufacturing Industries. National Bureau of Economic Research Working Paper \#3582 (January 1990).

National Bureau of Economic Research. The Price Statistics of the Federal Government. National Bureau of Economic Research. New York: Columbia University Press, 1961.

Pelaia, E. "IBM Terminal Prices". (1993) IBM Representative, personal communication.

Popkin, J., and Company. The Impact of Measurement and Analytical Issues in Assessing Industry Productivity and its Relation to Computer Investment . Mimeo, Washington, DC (October 1992).

Quinn, M.A., Craumer, M.A., Weaver, A., et al. Critical Issues of Information Systems Management for 1993. The Sixth Annual Survey of Information Systems Management Issues. Cambridge MA: CSC Index, 1993.

Roach, Stephen S. America's Technology Dilemma: A Profile of the Information Economy. Special Economic Study, Morgan Stanley (April 1987).

Scott Morton, M. (Ed.). The Corporation of the 1990s: Information Technology and Organizational Transformation. New York: Oxford University Press, 1991.

Siegel, D. and Griliches, Z. Purchased Services, Outsourcing, Computers and Productivity in Manufacturing. National Bureau of Economic Research Working Paper \#3678 (April, 1991).

Simon, Herbert A. On the Behavioral and Rational Foundations of Economic Dynamics. Journal of Economic Behavior and Organizations, Vol. 5, (1984), pp. 35-66.

Strassmann, P.A. The Business Value of Computers. Information Economics Press, New Canaan, Conn, 1990.

Thurow, L. Are Investments in Information Systems Paying Off? (interview). MIT Management (1990).

Varian, H. Microeconomic Analysis. W. W. Norton \& Company, Inc., New York, 1992.

Weill, P. The Relationship Between Investment in Information Technology and Firm Performance: A 
Study of the Valve Manufacturing Sector. Information Systems Research, Vol. 3, No. 4 (December 1992).

Wilson, D. Assessing the Impact of Information Technology on Organizational Performance. In R. Banker, R. Kauffman, \& M. A. Mahmood, Strategic Information Technology Managementt. Harrisburg, PA: Idea Group, 1993.

\section{Footnotes:}

[1] An observation is one year of data on all variables for a specific firm. We did not have all five years of data for every firm, but the data set does include at least one year of data for 367 different firms.

[2]However, output and GDP are not directly comparable because GDP is net of interfirm purchases. On a comparable basis (Value-Added), our sample represents approximately 13\% of the US economy in 1991.

[3] Specifically, the "management productivity of information technology" (MPIT) dataset, which surveyed 60 business units of 20 participating firms for the period 1978-1982.

[4] The precise definition of "IT" varies from study to study. Morrison and Berndt included scientific instruments, communications equipment, photocopiers and other office equipment as well as computers in their definition. Others define IT even more broadly, including software, services and related peripheral equipment. As described in section 2.3 below, the definition used in our study is fairly narrow and includes separate estimates for the effect of corporate computer capital and corporate IS labor.

[5] As the National Bureau of Economic Research (1961) put it: "If a poll were taken of professional economists and statisticians, they would designate the failure of price indexes to take full account of quality changes as the most important defect in these indexes." No good methodology exists for incorporating some of the other benefits, such as variety. Baily and Gordon (1988) estimate that "true" annual productivity growth might be as much as $0.5 \%$ higher overall than reported in official statistics.

[6] (Berndt, 1991) lists over a hundred references on this approach and presents an excellent literature review.

[7] Another common way to operationalize the theory is to use the production function to derive a "cost function" which provides the minimum cost required for a given level of output. While cost functions have some attractive features, they require access to firm-level price information for each input, which are data we do not have.

[8] A more complete model might include, in addition to these controls, other variables which may affect output such as the organization's maturity in the use of IT or the degree of restructuring it has undergone. We hope to explore such models in future research.

[9] For instance, a simple linear relationship between inputs and outputs is ruled out by these constraints. A linear production function implies that a firm will either use only the lowest cost input, or an indeterminate mix of all inputs if the prices are exactly the same.

[10] For instance, Hall (1993) introduces her Cobb-Douglas production function with the words: "...using the by now standard growth accounting framework...".

[11] Formally, the output elasticity of computers, EC, is defined as: . For our production function, F, this reduces to: . The ROI for computers is simply the output elasticity multiplied by the ratio of output to computer input: 
[12]For expositional simplicity, we write this equation with a single intercept [[beta]]0. In the actual analysis, this intercept is allowed to vary by year and industry or by year and sector.

[13] Sometimes also called IZEF, the iterated version of Zellner's efficient estimator, ISUR yields estimates that are numerically equivalent to the maximum likelihood estimator (Berndt, 1991). The ISUR procedure starts by estimating the coefficients by OLS to obtain an initial estimate of the error term covariance matrix, and then iteratively refines this estimate until convergence is reached at minimum error. This procedure implicitly corrects for serial correlation among the variables even when there are missing observations for some firms in some years. More traditional methods of correcting for serial correlation in panel data sets (Kmenta, 1986) require complete data and do not seem to perform well with short time dimensions.

[14]Specifically, the survey targets Fortune 500 manufacturing and Fortune 500 service firms that are in the top half of their industry by sales (see Table 2a).

[15]Compustat II provides financial and other related information for publicly traded firms, primarily obtained through annual reports and regulatory filings.

[16] Specifically, we estimated a figure for the value of terminals and the value of PCs and then weighted them by the proportion of PCs versus terminals. For terminals, the we estimated the value as the average list price of an IBM 3151 terminal in 1989 which is \$609 (Pelaia, 1993). For PCs we used the average nominal PC cost over 1989-1991 of $\$ 4,447$, as reported in Berndt \& Griliches (1990). These figures were then weighted by the proportion of PCs to terminals in the 1993 IDG survey (58\% terminals). The resulting estimate was $.42 * \$ 609+.58 * \$ 4,447=\$ 2,835$.

[17]An alternative measure of capital stock was computed by converting historical capital investment data into a capital stock using the Winfrey S-3 table. This approach was used in earlier versions of this paper (Brynjolfsson \& Hitt, 1993). However, the calculation shown above is more consistent with previous research (see e.g. (Hall, 1993)).

[18] For instance, the custom of treating checking accounts as "outputs" and interest bearing accounts as inputs was undermined when interest-bearing checking accounts were introduced.

[19] The impact of these changes in both cases was to lower the return to COMPUTER CAPITAL as compared to the results on the full sample.

[20] As noted in footnote 11, supra, , which in this case is .0169/.0209 $=.8086$ or about $81 \%$.

[21] It is worth noting that our approach provides estimates of the marginal ROI of each input: how much the last dollar of stock or flow added to output. In general, infra-marginal investments have higher rates of return than marginal investments, so the return to the first dollar invested in computers is likely to be even higher than the marginal returns we reported.

[22] We thank Dan Sichel for pointing this out.

[23] Technically, "negative capital gains" may be a more accurate term than "depreciation", since computer equipment is more likely to be replaced because of the arrival of cheaper, faster alternatives than because it simply wears out.

[24] As discussed in section 2, it is also possible that there are other "hidden" expenses associated with COMPUTER CAPITAL in addition to depreciation. On the other hand, firms invest in IT at least partly to move down the learning curve (Brynjolfsson, 1993) or create options (Kambil, Henderson \& Mohsenzadeh, 1993), and these effects may create "assets" as large as those lost to depreciation. The high 
gross returns to computer capital suggest that even if there were significant additional expenses associated with COMPUTER CAPITAL, its net returns would still be positive.

[25] A decline in the returns to COMPUTER CAPITAL between 1989 and 1990 is also evident in a balanced panel of 201 firms in the sample for 1989-1991.

[26] Note that if we had used OLS, further assumptions would be required: that all error terms are independent and constant variance over time.

[27] We were unable to do the White test for heteroskedasticity on these data because of limitations of our econometric software, and the large number of regressors.

[28] This is not the case if an input variable is systematically understated by a constant multiplicative factor. In this case, the coefficient estimates would be unchanged.

[29] However, in the presence of individual firm effects, lagged values are not valid instruments. While we did not test for firm effects, we suspect they may be important, and so the results of our 2SLS estimates should be interpreted with caution.

[30]The translog is a second order approximation to an arbitrary production function and contains for each input, the value of the input, the value of the input squared and all multiplicative interaction terms between the input and all other inputs. The Cobb-Douglas production function is a special case of the translog with the square and interaction terms restricted to be zero. For four factors of production, the full translog requires that 14 coefficients be estimated (not including intercepts).

[31]The elasticity for computer capital can be calculated for the "average" firm in the sample by taking the partial derivative of output with respect to COMPUTER CAPITAL for the translog specification, and substituting the appropriate coefficient estimates and average factor input values.

[32] Multicollinearity diagnostics (Belsey, 1991) also indicated that most of the added terms in the translog were highly collinear, which could account for the higher standard errors.

[33] This is because multiplicative scaling of a regressor in a logarithmic specification will not change the coefficient estimate or the standard error. All the influence of the multiplier will appear in the intercept term which is not crucial to our analysis.

[34] The MIT Center for Coordination Science and International Financial Services Research Center jointly sponsored a Workshop on IT and Productivity which was held in December, 1992. 